\title{
Drying tea in a kilburn vibro fluid bed dryer
}

\author{
M. Akhtaruzzaman, M. R. Ali ${ }^{*}$ M. M. Rahman ${ }^{1}$ and M. S. Ahamed \\ Department of Farm Power and Machinery, Bangladesh Agricultural University, Mymensingh-2202, Bangladesh and \\ ${ }^{1}$ Department of Food Engineering \& Tea Technology, Shahjalal University of Science \& Technology, Sylhet, \\ Bangladesh, *Email: engr_rustomfpm@yahoo.com
}

\begin{abstract}
The fluidized bed drying principles for drying of tea in Bangladesh is thoroughly studied. The experiments were conducted to determine the drying curve, drying time, drying constant and dynamic equilibrium moisture contents of tea at the Bangladesh Tea Research Institute. Drying of tea in a fluidized bed dryer (Kilburn Vibro Fluid Bed Dryer) takes only 20 min for drying from an initial moisture content of $69.1 \%$ to a final moisture content of $2.8 \%$. Temperatures of drying air were recorded to be $130^{\circ} \mathrm{C}$ at the inlet and $90^{\circ} \mathrm{C}$ at the outlet. The drying constant was found to be $31.05 \mathrm{~h}^{-1}$ and the dynamic equilibrium moisture contents were in the range of 18.3 to $2.0 \%$. Finally the principle of fluidized bed drying was compared with the principle of conventional endless chain pressure type drying.
\end{abstract}

Keywords: Tea, Moisture content, Drying, Fluidized bed dryer, Drying rate constant

\section{Introduction}

Tea is one of the major agricultural produces of Bangladesh. The total earning from tea export in 2011-12 fiscal year was US\$ 3.38 million. Annual export is about 25 million $\mathrm{kg}$ and annual domestic consumption is about 23 million $\mathrm{kg}$ (Shabbir and Saradat, 2010). It is used as a very popular beverage all over Bangladesh like many other countries in the world. Tea industries are spread over five continents in units of various sizes. A large number of chemical and bio-chemical reactions take place in tea processing and these reactions are critical to maintain the quality of the final product such as flavor and color. This emphasizes the importance of the interrelationship of bio-chemical reactions of tea with engineering aspects of drying.

Drying is a simultaneous heat and mass transfer process, where heat is supplied to wet tea by heated air and the evaporated moisture is carried away by the air. The purposes of drying tea are to hold fermentation, remove moisture and produce good quality tea with good keeping quality. Fermented tea is dried in a conventional tray dryer from about $65-70 \%$ to $2.5 \%$ moisture content when the inlet hot air temperature ranges from $123^{\circ} \mathrm{C}$ to $126^{\circ} \mathrm{C}$. Tea dried at high temperatures are deficient in pungency, quality and flavor, but their keeping properties are satisfactory. In contrary tea can be satisfactorily dried at temperatures as low as $71^{\circ} \mathrm{C}$ provided the final moisture content is correct. This tea retains quality and flavor but deteriorate on storage. If the tea is dried below 1.0 per moisture content, it loses some quality and on the other hand, tea dried to 3.5 per cent moisture content and above does not keep well. So the drying conditions play an important role in determining the quality (Eden, 1976).

The principle involved in the conventional dryers is that fermented leaf is subjected to a blast of hot air in such a manner that the hottest air first comes in contact with the tea having the least moisture content. In these dryers, the fermented leaf falls on a series of moving perforated trays on which it is passed and repassed through a moving stream of hot air. The design is such that at each stage of the drying operation, the leaf is subjected to a different temperature. As the leaf passes from tray to tray, it progressively comes into contact with higher temperatures. If the exhaust temperature is greater than $57.2^{\circ} \mathrm{C}$ the rate of moisture removal is too rapid and results in case hardened tea in which the particles are hard on the outside but inside is incompletely dried; such teas yield will be harsh in liquors and do not keep well. So it is paramount importance to ensure that temperatures are kept steady to the extent possible.

On the contrary, tea industry presently enjoys a variety of fluidized bed drying equipments like vibro-bed, five zones and three zones cross flow fluid bed dryers. All of them strive to get increased fuel economy without affecting quality. One of the virtues of fluidized systems is that have high rates of heat and mass transfer while maintaining uniform temperature characteristics on the bed. Consequently conditions such as case-hardening are seldom encountered with fluidized systems. In fluidized bed drying, it is possible to obtain good thermal contact between the tea particles and the drying medium results in improved fuel 
performance. Particle to particle attraction in a fluidized dryer is minimized because each particle is surrounded by its own fluid cushion. For knowing details about performance of fluidized bed dryer, it is necessary to conduct study on the fluidized bed dryer for clear understanding to get quality tea. This article provides details information about performance of the fluidized bed dryer through the following objectives: i) to obtain primary knowledge on fluidized bed drying of tea, ii) to determine drying curve, drying rate and drying rate constant of tea on fluidized bed dryer, and iii) to determine dynamic equilibrium moisture contents of tea.

\section{Materials and Methods}

The experimental study of fluidized bed drying of tea was conducted at Bangladesh Tea Research Institute (BTRI) located at Srimangal under the district of Moulavibazar, the tea growing area at the NorthEastern part of Bangladesh. A fluidized bed dryer (Kilburn Vibro Fluid Bed Dryer -KVD-A-1333) of BTRI was used for the experiment. A simplified arrangement and assembly of fluidized bed dryer is shown in Fig.1. It consisted of a heater system, a centrifugal type hot air blower, outlet hot air duct, a feed system, drive and excitation system, plenum chamber, drying chamber, exhaust and de-dusting systems and a cyclone system. The feed system enabled to regulate the feed of fermented leaf to the dryer and breaking up of lumps in the leaf. The plenum chamber consisted of galvanized steel and fully insulated chamber with the provision of two-temperature drying, where the first portion supplied hot air between $100-140^{\circ} \mathrm{C}$ while the second portion supplied cold air between $90-120^{\circ} \mathrm{C}$. Drying of tea took place in one pass across the closed drying chamber comprising of two perforated stainless steel plates, longitudinal plates, discharge weir plate, and discharge hopper. The duplex cyclone system is capable to separate tea dust and fibers from air before exhaust. The recommended operating temperatures of the dryer were as follows:

$\begin{array}{llcl}\text { Inlet 1 } & T_{1} & 130-140^{\circ} \mathrm{C} & \text { Refers to inlet air in zone I } \\ \text { Inlet 2 } & T_{2} & 100-108^{\circ} \mathrm{C} & \text { Refers to inlet air in zone II } \\ \text { Exhaust 1 } & T_{3} & 43-47^{\circ} \mathrm{C} & \text { Refers to feed rate } \\ \text { Exhaust 2 } & T_{4} & 85-90^{\circ} \mathrm{C} & \text { Refers to moisture of made tea }\end{array}$

The temperature, $T_{3}$ should be as low as possible so as to get best capacity and $T_{4}$ should be as high as possible to get well fried teas. $T_{3}$ and $T_{4}$ together offer effective control of fluidized bed dryer.

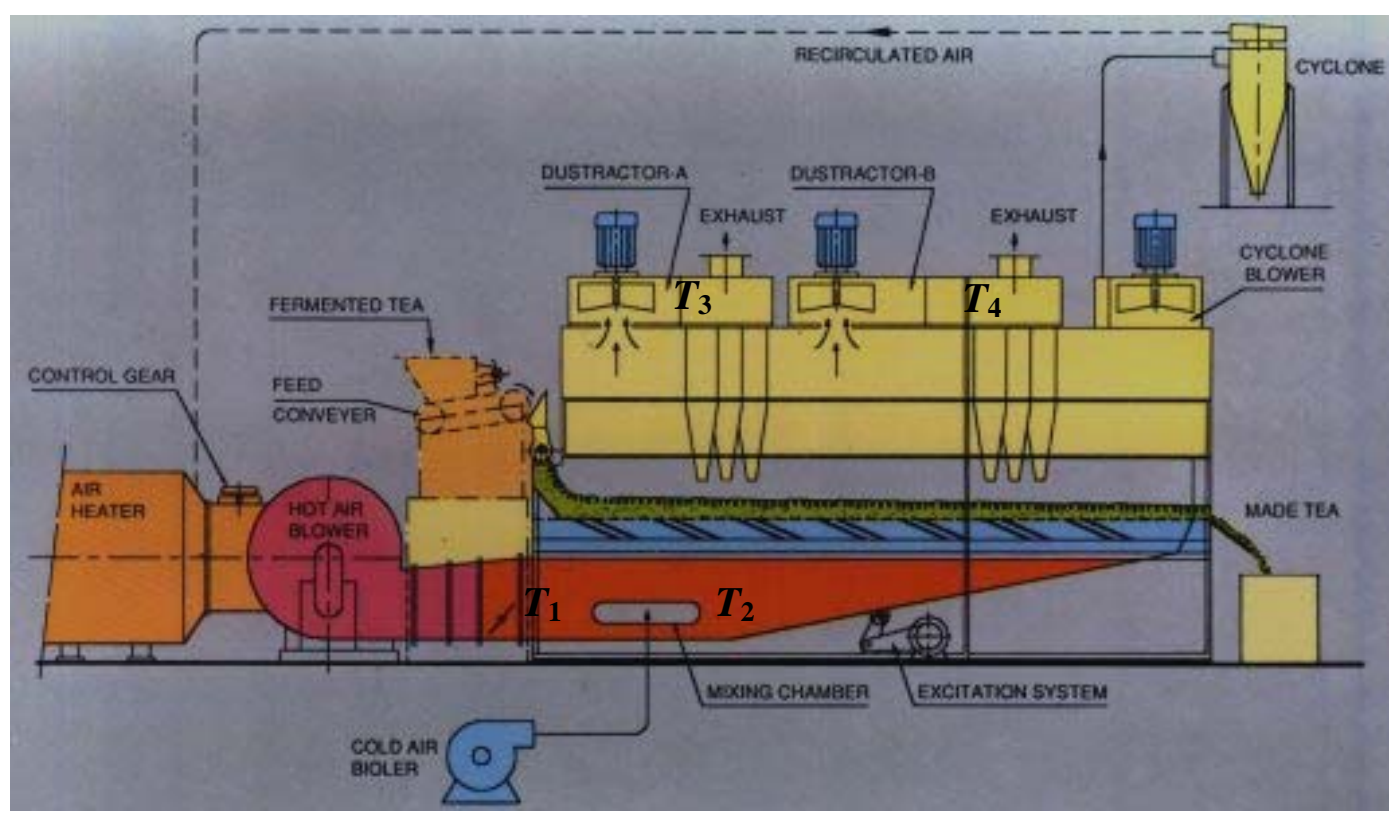

Fig. 1. General arrangement and assembly of Kilburn Vibro Fluid Bed Dryer - KVD-A-1333 
Moisture content of tea was determined by infrared lamp method and expressed in dry basis. Samples were collected manually from $0,0.61,1.22,1.83,2.44,3.05,3.66,4.27$, and $4.88 \mathrm{~m}$ distances of the dryer bed. Measurements were replicated four times and the average value was taken as the test data. The retention time was $20 \mathrm{~min}$ as the tea passes through $4.88 \mathrm{~m}$ bed. It was assumed that tea flows over the dryer bed and feeding rate was uniform. So it is required $2.5 \mathrm{~min}$ to pass a distance of $0.6 \mathrm{~m}$ along the bed of the dryer. The dry bulb and wet bulb temperatures were also determined by a laboratory psychrometer.

\section{Results and Discussion}

Moisture contents of tea were determined by taking samples from different locations of the $4.88 \mathrm{~m}$ long dryer bed. Samples were collected from 0, 0.61, 1.22, 1.83, 2.44, 3.05, 3.66, 4.27, and $4.88 \mathrm{~m}$ distances from the inlet of the dryer bed. The retention time was $20 \mathrm{~min}$ when tea passed through $4.88 \mathrm{~m}$ bed. The relationship among the moisture content, drying time and position of drying bed is shown in Fig. 2.

The average values of initial and final moisture contents of tea were found $69.1 \%$ and $2.8 \%$, respectively. The moisture profile of tea along the bed of the fluidized bed is shown in Fig. 2. According to Fig. 2, the moisture content of the fermented leaves decreased as the time and distance from the feeding point along the dryer increased. This was happened due to the long travel time of tea along the hot air bed of the dryer. According to Fig. 2, the decreasing nature of moisture content at constant rate was found within $2.5 \mathrm{~min}$ after that the drying rate is decreased exponentially. This indicates that the less tightly bound water from high moisture material is evaporated quickly due to application of heat energy and it is called first falling rate period. After that it is required higher heat energy to release tightly bound water from the material and it is called second falling rate period.

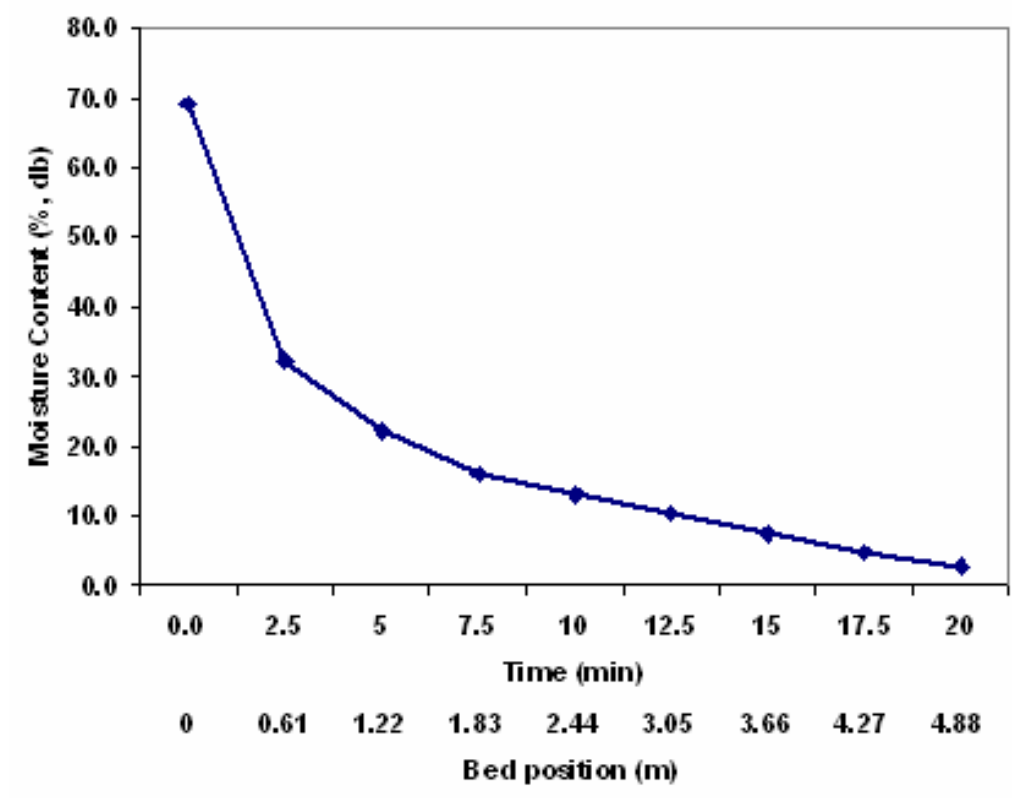

Fig. 2.The relationship among the moisture content, drying time and bed position

\section{Drying rate and drying rate constant}

Drying is the process of removing water from the materials to be dried by evaporation. During the early stages of drying, the tea was wet with a continuous film of water existing over the entire surface. The water removed in this period was mainly superficial water. During this period the rate of drying under the given set of air conditions was constant and independent of the moisture content. This is known as the constant rate drying period and the temperature of the materials during this period approached the wet bulb temperature of the air. The magnitude of the constant rate drying depends on the area exposed to 
the drying medium, the difference in temperature between the air stream and the wet surface of the solid and the air velocity. Figure 3 shows the drying rate of tea in the fluidized bed dryer. According to Fig. 3, A to $B$ is the constant-rate period, $B$ to $C$ is the first falling rate period and $C$ to $D$ is the second falling rate period of drying. The rate of moisture removal was high up to a moisture content of $30 \%(\mathrm{db})$. The prediction of drying rate is important for designing a drying system.

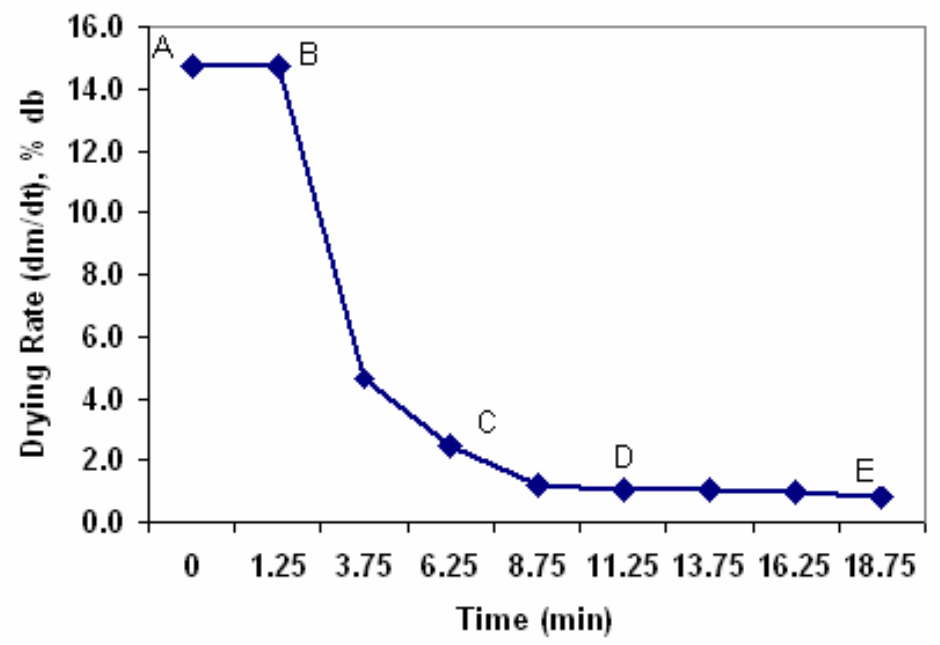

Fig. 3. The relationship between drying rate and time

Drying rate constant, which is a function of drying air temperature, was obtained from thin layer drying equation. Several researchers (Simmonds et al., 1953; O'Callaghan, 1954; Boyce, 1956; Kachru et al., 1971; Watson and Bhargara, 1974; Bala and Woods, 1984) have proposed the following single exponential equations:

$$
\frac{M-M_{e}}{M_{0}-M_{e}}=e^{-k t}
$$

For a change of moisture content from $M_{1}$ to $M_{2}$ over an interval $t_{1}$ to $t_{2}$, Eq. 1 can be expressed as:

$$
\begin{array}{r}
\frac{M_{1}-M_{e}}{M_{0}-M_{e}}=e^{-k t_{1}} \\
\text { and } \frac{M_{2}-M_{e}}{M_{0}-M_{e}}=e^{-k t_{2}}
\end{array}
$$

From Fig. 2, the values of moisture content are $M_{1}=32.2 \%$ and $M_{2}=22.1 \%$ at $t_{1}=2.5 \mathrm{~min}$, at $t_{2}=5 \mathrm{~min}$, respectively and initial moisture content is $M_{0}=69.05 \%$. By substituting these values in Eqs. 2 and 3 , the value of equivalent moisture content, $M_{\mathrm{e}}$ was found as $18.28 \%(\mathrm{db})$ and the value of drying rate constant, $k$ was found as $31.05 \mathrm{~h}^{-1}$. The value of $k$ is much higher than grains. This is because tea is leafy and soft.

\section{Dynamic equilibrium moisture content}

The following Eq.4 can be obtained through Eq.3 divided by Eq.2.

$$
\frac{M_{2}-M_{e}}{M_{1}-M_{e}}=e^{-k\left(t_{2}-t_{1}\right)}
$$

Equation 4 can be rewritten as:

$$
\frac{M_{1}-M_{2}}{M_{1}-M_{e}}=1-e^{-k\left(t_{2}-t_{1}\right)}
$$

Substituting $M_{2}-M_{1}=\Delta M$ and $t_{2}-t_{1}=\Delta t$ and Eq. 5 simplified as:

$$
\mathrm{M}_{\mathrm{e}}=\mathrm{M}_{1}+\Delta \mathrm{M} /\left(1-\mathrm{e}^{-\mathrm{k} \Delta \mathrm{t}}\right)
$$


The dynamic equilibrium moisture content (EMC) over each interval of time was computed using Eq.6. The EMC values were plotted against time as shown in Fig.4. The dynamic equilibrium moisture content decreases with the increase of drying time. The value of EMC varies from 18.3 to $2 \%$ according to Fig. 4 .

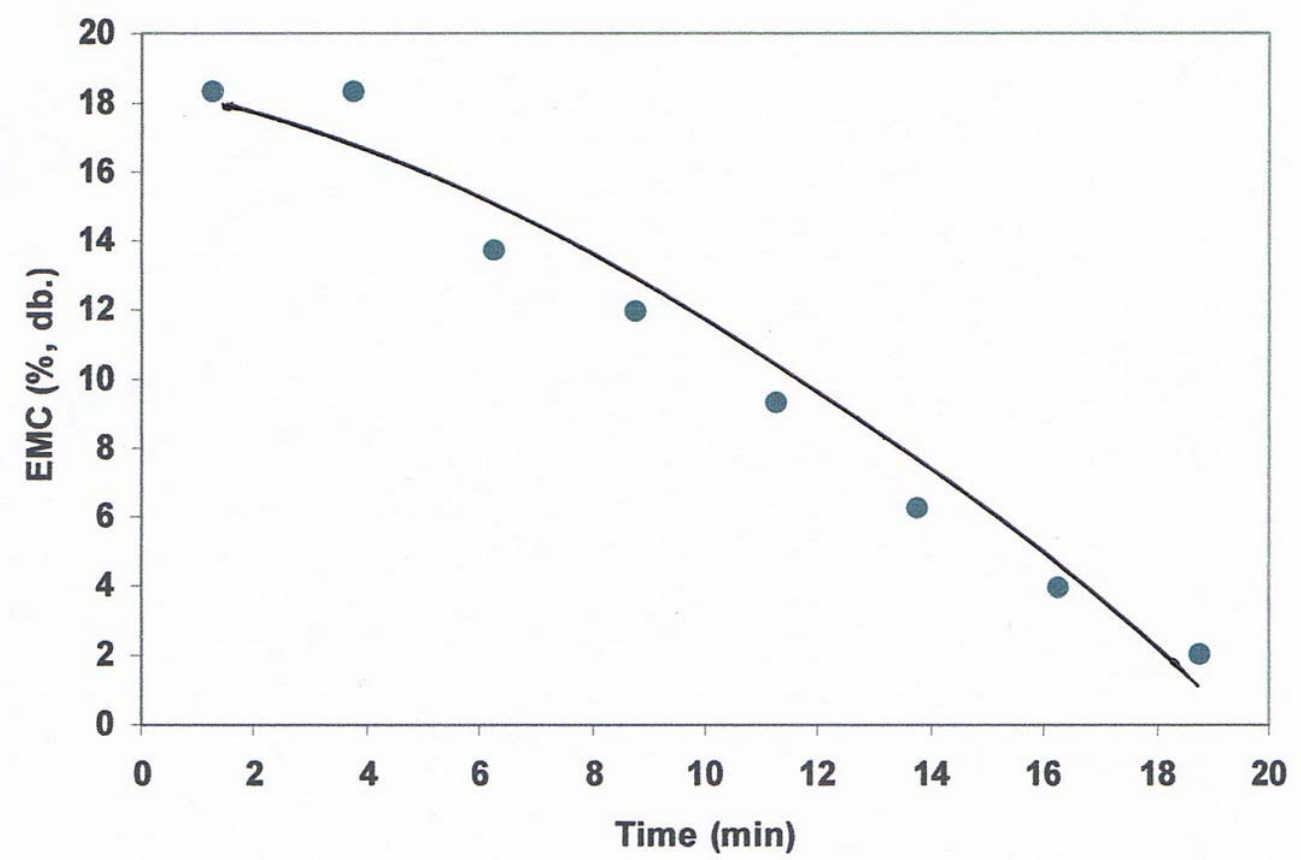

Fig. 4. The dynamic equilibrium moisture content (EMC) of tea

The schematic diagram of endless chain pressure (ECP) type conventional dryer is shown in Fig. 5 . The ECP type dryer is very rare in Bangladesh. The ECP dryer consists of two or three individual tray circuit. When the leaf is fed into the feeding circuit, the spreader spreads the leaf uniformly on the tray. The leaf completes the run on the top circuit and leaf falls on the mid circuit where direction of tray movement is opposite to that of top circuit. Thus the leaf is subjected to gradual high temperature from top to bottom circuit and drying is completed when leaf reaches the bottom circuit. The total drying time in this dryer is 20-22 min. The output of the dryers is $200-250 \mathrm{~kg}$ made tea with the feeding moisture level of $55 \%$. The inlet and exhaust temperatures may be maintained at $100^{\circ} \mathrm{C}$ and $55^{\circ} \mathrm{C}$, respectively (Ramu, 2000).

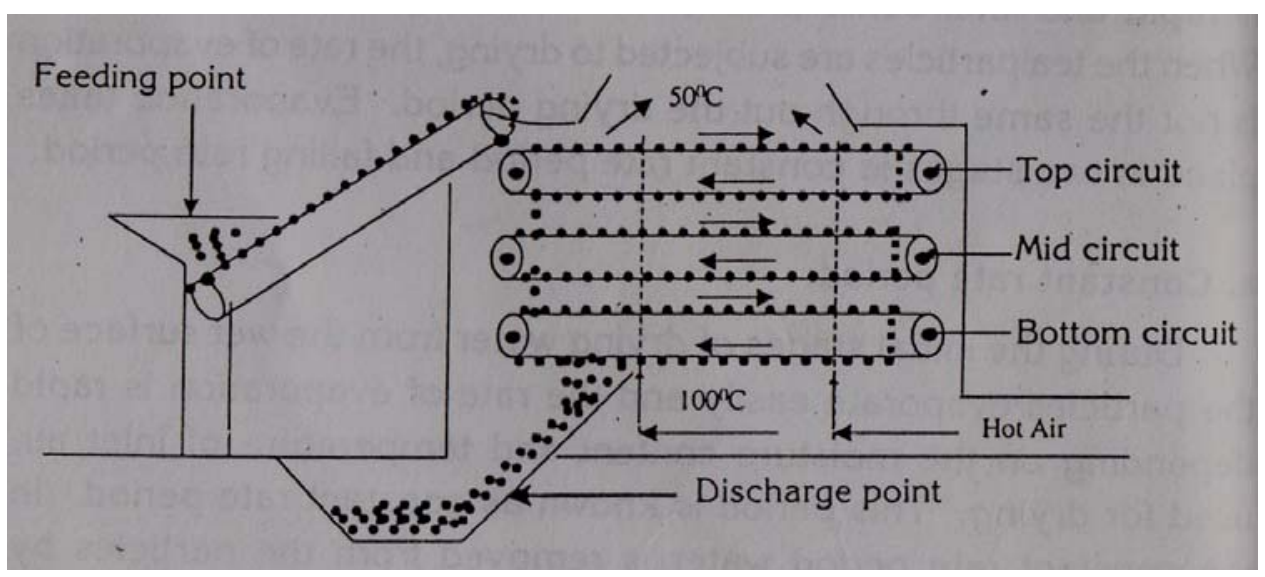

Fig. 5. Endless chain pressure (ECP) type conventional dryer (Ramu, 2000) 
In the tea industry, the most frequently applied dryer is the fluid-bed dryer followed by the ECP dryer. The fluid bed dryer is a popular method of drying. The fluid bed dryer is therefore the best choice for drying of macerated tea particles, in all respects apart from electrical power consumption. Unfortunately, the cost of electrical power, both in capital and running costs, is a major contributor to the cost of operating a tea factory. However, in balance, the fluid bed dryer can still be considered the best technology available at present (Temple, 2000).

\section{Conclusion}

The fluid bed dryer or kilburn vibro fluid bed dryer is popular in tea industry in all respects apart from electrical power consumption. From the study, it is possible to conclude that tea dried at high temperatures $\left(130-140^{\circ} \mathrm{C}\right)$ for a short period $(20 \mathrm{~min})$ can retain their quality and flavor and longtime storage without deterioration. The drying rate constant, $k$ is $31.05 \mathrm{~h}^{-1}$ and the dynamic equilibrium moisture content ranged from 18.3 to $2.0 \%$. The experimental results presented here will be useful for dryer design and further study on drying of tea.

\section{Acknowledgement}

We would like to acknowledge the Bangladesh Tea Research Institute (BTRI) for providing facilities to conduct the experiment.

\section{References}

Bala, B.K. and Woods, J.L. 1984. Simulation of deep bed malt drying. J. Agril. Eng. Research. 30: 235-244.

Boyce, D.S. 1956. Heat and moisture transfer in ventilated grain. Ph.D. Thesis. University of Newcastle Upon Tyne.

Eden, I. 1976. Tea, Third ed., Longman, London, pp. 8 -16.

Kachru, R.P., Ojha, T.P. and Kurup, G.T. 1971. Drying characteristics of Indian paddy varieties. J. Agril. Eng. 8:16-23.

O'Callaghan. 1954. Drying of wheat grain: effects of air condition on through drying. M.Sc. Thesis. University of Durham.

Ramu, R. 2000. Tea factory manual. Krishi Vigyan Kendra, The united Planters' Association of Southern India, Coonoor-643101, Nilgiris.

Shabbir, S.M. and Sa'adat, N. 2010. Expansion of tea production and export from Bangladesh: some policy suggestion. Thoughts on Economics. 16:67-76.

Simmonds, W.H.C., Ward, G.T. and McEwen, E. 1953. The drying of wheat grain. Part I: The mechanism of drying. Trans. Inst. Chem. Eng. 31: 265-278.

Temple, S.J. 2000. Control of fluidized bed tea drying. PhD thesis, Wageningen University, Netherland.

Watson, E.L. and Bhargava, V.K. 1974. Thin layer studies on wheat. Canadian Agril. Eng. 16:18-22. 